Denise da Conceição da Costa $^{1}$

Nilton Luiz Menegon ${ }^{2}$

\section{Condução de ações em Saúde e Segurança do Trabalho em pequenas e médias empresas: análise de três casos*}

\author{
Three case studies on Health and Safety actions in small and \\ medium size enterprises
}

\begin{abstract}
${ }^{1}$ Departamento de Fisioterapia do Instituto Metodista Bennett.

${ }^{2}$ Departamento de Engenharia de Produção da Universidade Federal de São Carlos (UFSCar).

*Artigo baseado na dissertação de mestrado de Denise da Conceição da Costa intitulada Atenção à saúde nas pequenas e médias empresas de São José dos Campos: um estudo de caso, apresentada em 2007 ao Departamento de Engenharia de Produção da Universidade Federal de São Carlos.
\end{abstract}

Contato:

Denise da Conceição da Costa

Rua Maria José do Amaral Alves, 65, Floradas da Serra, Urbanova V

São José dos Campos, SP

E-mail:

denise@dep.ufscar.br

\section{Resumo}

Construir ações relacionadas à saúde e segurança nas Pequenas e Médias Empresas (PME) não é tarefa fácil, uma vez que essas empresas precisam lidar com o provimento deficitário de informações, poucos recursos disponíveis e metodologias de ação desenvolvidas de acordo com as características das empresas de grande porte. Partindo de estudos de caso e de metodologia qualitativa, o presente estudo teve como objetivo investigar, em três PME do setor industrial, a maneira como ações de saúde e segurança são conduzidas - inclusive ações ergonômicas -, bem como as justificativas para sua forma de condução, utilizando, para tanto, entrevistas e questionários. A investigação comprovou que aspectos, tais como poucos recursos financeiros, pouco acesso à informação, cultura e o modelo gerencial assumido, exercem grande influência sobre a forma como as ações em Saúde e Segurança do Trabalho (SST) serão conduzidas, sendo que a Ergonomia, quando houver, será caracterizada pela condução perceptiva e informal das mudanças no local de trabalho. Concluiu-se que algumas normas e leis, assim como ferramentas ergonômicas, deveriam ser desenvolvidas e adaptadas às PME. Moldar as ações segundo as necessidades e limitações de cada empresa poderia facilitar sua utilização e assim promover uma melhora das condições de saúde e segurança nas PME.

Palavras-chaves: Ergonomia, Saúde e Segurança do Trabalho (SST), Pequenas e Médias Empresas (PME).

\begin{abstract}
Building actions related to health and safety in small and medium size enterprises (SME) is not an easy task, since these companies need to face lack of information, short availability of resources and methodologies developed for the characteristics of a big company. Based on case study techniques and a qualitative approach, the present study aims at investigating, through interviews and questionnaires, not only the way health and safety interventions - including ergonomics - are carried on in three industrial sector SMEs, but also the reasons for their being conducted that way.

This investigation led us to conclude that short resource availability, difficulty in accessing information, the company phylosophy and managerial model, greatly influence the way Health and Safety (OSH) actions are conducted in small companies; and changes on work place, if Ergonomics is considered, will be guided by perception and based on informality. The authors conclude that laws, regulations and ergonomic tools to fit SMEs should be created. Adapting these actions accordingly to the needs and limitations of each company would probably make them easier to be followed and, as a consequence, would improve health and safety at SMEs.
\end{abstract}

Keywords: Ergonomics, Occupational Safety and Health (OSH), Small and Medium Enterprises (SME).
Revisado: 02/06/08

Aprovado: 09/06/2008 


\section{Introdução}

Hoje é reconhecida a real importância das Pequenas e Médias Empresas (PME) para a economia nacional. As PME são comprovadamente contribuintes na geração de empregos, fornecimento de produtos para o mercado consumidor e geração de tecnologia (BORTOLI NETO, 1980; LA ROVERE, 2001; RODRIGUES, 2000; SERVIÇO BRASILEIRO DE APOIO ÀS MICRO E PEQUENAS EMPRESAS, 2005), sendo elas responsáveis, de acordo com Rodrigues (2000), por quase $60 \%$ das ocupações no país. O fato das PME empregarem muito se deve, em grande parte, ao baixo custo para geração de postos de trabalho, bastante inferior ao das grandes empresas, o que abre grandes perspectivas para políticas oficiais de geração de empregos, principalmente em momentos recessivos (VILLELA; AMADEO, 1994).

As PME possuem características próprias, diferenciando-se das grandes empresas não apenas em tamanho, mas em termos estruturais e organizacionais; ao mesmo tempo, apresentam grande heterogeneidade entre si. Essa heterogeneidade é identificada, principalmente, em termos de capacidade inovativa, havendo diferenças também quanto às questões organizacionais e capacidade de alavancar os negócios (BORTOLI NETO, 1980; UNIÃO EUROPÉIA, 1999 apud LEMOS, 2003). Dentre as particularidades em relação às grandes, estão a limitada base de recursos (financeiros, humanos, técnicos, tecnológicos e de gestão), a cultura organizacional singular e a menor habilidade em influenciar as relações com o ambiente externo, o qual inclui clientes, fornecedores, mercados de trabalho, agências de promoção, fomento e financiamento (UNIÃO EUROPÉIA, 1999 apud LEMOS, 2003). Por outro lado, podemos citar, como vantagens em relação às grandes empresas, a grande capacidade de absorção da mão-de-obra a baixo custo, com menores exigências de qualificação, e a alta flexibilidade.

Outra característica que torna as PME diferenciadas é a forma de gerenciamento. Primeiro, o quadro administrativo diferencia-se muito do encontrado nas grandes corporações, conforme discutido por Pinheiro (1996), havendo menos níveis hierárquicos à medida que diminui o porte da empresa e, em geral, menor especialização e qualificação de seus funcionários e gerentes. Em segundo lugar, o grau de formalização, muitas vezes, é mínimo, gerando relações de trabalho informais, o que pode comprometer a qualidade e a agilidade na realização das atividades (CARDOSO, 1998).

Em virtude de todas as características que diferenciam as pequenas empresas das grandes, é natural pensar que os preceitos - tais como mecanismos gerenciais e acesso a créditos -, desenvolvidos com base nas segundas, não se adaptem às primeiras. No que se refere aos mecanismos gerenciais, Torrès (1998), citado por Lemos (2003), claramente apóia esta idéia ao falar da impossibilidade de se aplicar às pequenas empresas os ensinamentos e os preceitos da gestão das grandes empresas, já que as primeiras não são miniaturas das segundas, sendo necessário desenvolver ações de acordo com suas particularidades. Opinião apoiada ainda por Carvalho (2004), que diz que a dificuldade em aplicar modelos gerenciais nas pequenas empresas talvez ocorra devido à ausência de metodologias adequadas às suas características, uma vez que os modelos existentes espelharam-se nas grandes corporações; faz-se necessário, segundo a autora, compreender as características específicas desses ambientes para que as ações sejam direcionadas de acordo com a realidade das empresas menores. Tratando-se das dificuldades de acesso a créditos bancários para impulsionar o crescimento, Lemos (2003) credita o problema ao fato de as políticas de financiamento e os mecanismos de apoio terem sido concebidos para atendimento a empresas de grande porte, sendo que a exigência de garantias e a necessidade de estar em dia com as obrigações fiscais excluem a maioria das PME.

Diante das particularidades das PME e da dificuldade de adequação de instrumentos e preceitos desenvolvidos com base em grandes empresas, relatados na literatura, o presente estudo teve como objetivo compreender e discutir os fatores relacionados às condições de saúde nas pequenas e médias empresas, considerando, para tanto, não só a percepção que os líderes e responsáveis por Saúde e Segurança do Trabalho (SST) guardam sobre a importância dos mesmos, mas também as dificuldades e facilidades enfrentadas para a inserção de ações em SST e ergonômicas em três PME do setor industrial da cidade de São José dos Campos/SP.

\section{A questão da saúde e segurança nas PME}

Torp e Moen (2006) relatam que a maioria dos países possui legislação protegendo os trabalhadores de riscos no trabalho. Na Dinamarca, por exemplo, a lei prescreve aos empregadores que estabeleçam um ambiente seguro, sendo sua tarefa, em cooperação com empregados, garantir a avaliação do local de trabalho (JENSEN et al., 2001). Do mesmo modo, o Brasil possui diversas medidas de manutenção de saúde e segurança, tais como as Normas Regulamentadoras do Trabalho (NR), além de eventuais programas em saúde e segurança.

A Consolidação das Leis do Trabalho (CLT) de nosso país, em seu capítulo V, estabelece diretrizes para um ambiente de trabalho seguro e saudável. Além de determinar que o órgão de âmbito nacional competente em matéria de Segurança e Medicina do Trabalho deve estabelecer normas em saúde e segu- 
rança ocupacional e controlar a fiscalização, também determina que as empresas devem cumprir e fazer cumprir as normas relacionadas à saúde e segurança, instruindo seus empregados quanto aos procedimentos de segurança e manutenção da saúde. Estes, por sua vez, devem observar as normas colocadas e fazer cumpri-las juntamente com a empresa. A CLT determina também que, dependendo do número de funcionários e da periculosidade das atividades desenvolvidas, a empresa deverá constituir uma Comissão Interna de Prevenção de Acidentes (CIPA), composta por representantes do empregador e dos empregados, e manter Serviços Especializados em Engenharia de Segurança e em Medicina do Trabalho - SESMT (CAMPANHOLE; CAMPANHOLE, 1993).

A maior deficiência quanto ao cumprimento das normas em SST por parte das empresas de menor porte em relação às empresas maiores é fato verídico em países desenvolvidos ou em desenvolvimento. Jensen et al. (2001) dizem que geralmente as firmas menores não seguem as regras estabelecidas pelas normas de saúde e segurança. Como exemplo, podemos citar os estudos de Champoux e Brun (2001), que demonstraram que a abordagem à gestão em SST na Pequena Empresa (PE) não é sistemática, a seleção dos problemas a resolver é feita de maneira arbitrária e a PE tende a utilizar medidas de controle pouco elaboradas. Algumas empresas gerenciam a atenção à saúde ocupacional somente direcionando ações em segurança - destacando-se o uso de Equipamentos de Proteção Individual (EPI) -, havendo frustração entre muitos empregadores ao perceberem que os EPI fornecidos não são amplamente utilizados (BRADSHAW et al., 2001; CHAMPOUX; BRUN, 2001; RONGO et al., 2004).

Apesar da dificuldade de cumprimento integral das normas, as pequenas empresas, em geral, apresentam uma vantagem sobre as grandes empresas quanto à morbidade de suas atividades: como há poucos funcionários e uma diversidade de atividades a serem realizadas, os trabalhos podem ser alternados e variados e o efeito de posturas extremas e repetição de movimentos pode ser aliviado (WALTARI et al., 1980). Por outro lado, os acidentes são proporcionalmente mais freqüentes nas empresas de menor porte (EUROSTAT, 2000 apud DE KOK, 2005).

Considerando que muitas empresas (principalmente as de menor porte) não conduzem ações em saúde e segurança adequadamente, havendo deficiências no cumprimento das normas impostas, é comum, nos achados da literatura, pesquisadores alegarem que faltam educação e treinamento nas empresas menores, o que resulta em prejuízos às ações em saúde e segurança, devendo haver maior responsabilidade das empresas sobre a saúde de seus empregados (JOHANSSON; JOHANSSON, 1992; CHAMPOUX; BRUN, 2001; JENSEN et al., 2001). São freqüentes, também, relatos quanto às limitações econômicas existentes nas firmas menores, as quais tornam difícil esperar um alto grau de atividade em termos de saúde (SOHN et al., 1998; CHAMPOUX; BRUN, 2001; JENSEN et al., 2001). Jensen et al. (2001) consideram, entretanto, que a falta de recursos e de informações não é o maior impedimento à adoção de políticas de saúde e segurança no ambiente de trabalho, sendo necessário qualificar apenas uma pessoa de dentro da empresa a partir de um treinamento para que esta controle as ações de SST, conduzindo ações e gerenciando a informação.

Um grande empecilho às ações de SST no ambiente de trabalho pode ser, entretanto, relacionado à natureza dos programas hoje existentes em todo o mundo. Jung (1999) acredita que as diferenças entre pequena, média e grande empresas demandam atividades desenvolvidas de acordo com o tamanho da empresa e as características de cada local de trabalho. Torp e Moen (2006) concordam com Jung (1999) ao dizer que o sistema de gerenciamento de ações em saúde e segurança deveria se adaptar ao tamanho e às necessidades da companhia, sendo que a menor complexidade estrutural das empresas menores não demandaria, de acordo com o estudo, tanto em termos de exigência estrita das normas.

É importante frisar a importância de se adaptar programas de SST não somente ao tamanho da empresa, mas também às necessidades, especificidades e limitações de cada PME. Champoux e Brun (2001) identificaram, na França, que a dificuldade de homogeneização das pequenas empresas limita a aplicação de programas que foram desenvolvidos especialmente para as mesmas, sem, entretanto, considerar as diferenças que as $\mathrm{PE}$ guardam umas das outras. Cada empresa requer diferentes níveis de cobertura, dependentes do tamanho, dos processos operados, do trabalho com riscos conhecidos e previamente identificados (BRADSHAW et al., 2001), sendo pertinente perguntar até onde as propostas de ação nas empresas estão ajustadas aos seus constrangimentos e facilidades (JOHANSSON; JOHANSSON, 1992).

\section{A Ergonomia e a PME}

A Ergonomia é uma disciplina que visa à compreensão das interações entre humanos e outros elementos de um sistema, aplicando teoria, princípios, dados e métodos para projetar e aperfeiçoar o bemestar humano e o desempenho do sistema global, considerando fatores pertinentes aos aspectos físicos, cognitivos, sociais, organizacionais, ambientais e outros (INTERNATIONAL ERGONOMICS ASSOCIATION, 2003).

Mesmo contribuindo não apenas para a melhoria nas condições de saúde e segurança dos trabalhadores, mas também para melhorias na performance e produtividade da empresa, a Ergonomia apresenta dificuldades em inserir-se nas empresas de menor porte. Apesar da clara vantagem trazida por uma in- 
tervenção, Waltari et al. (1980) dizem que, do ponto de vista ergonômico, o lay-out do posto de trabalho e a produção das PME são pouco planejados, sendo os conceitos de Ergonomia pouco familiares às pequenas empresas, ao contrário do que acontece na maioria das grandes empresas. Contesta-se, muitas vezes, a falta de Ergonomia nas PME, alegando que, se houvesse tal estudo, grande parte desses problemas poderiam ser detectados e evitados. Considerando que uma ação ergonômica mostra seus resultados de forma mais clara nas empresas menores, com ganhos na produtividade, já que as ações são mais interligadas e as reações mais visíveis, fica difícil entender, à primeira vista, porque ela encontrase ausente nesses ambientes.

Já em 1984, a propósito da Ergonomia em PME, era feita a constatação de que a Ergonomia "nasceu e desenvolveu-se em sistemas de maiores dimensões" (BONNIN; BEDR, 2001), o que justifica o fato das ferramentas de análise pertencentes à Abordagem Clássica da Ergonomia e da Análise Ergonômica do Trabalho (AET) encontrarem dificuldades em inserir-se nas empresas de menor porte: a primeira por não possibilitar análises centradas no social - uma das demandas de análise das PME; a segunda pelo seu alto custo. Além disso, na PME há ausência formal de competências internas que possam apoiar a Ergonomia (BONNIN; BEDR, 2001). Essa ausência diz respeito à gestão econômica, à organização, à regulamentação e ao funcionamento humano, o que implica em uma gestão que se apóia, sobretudo, no sentido implícito das coisas. O comportamento e as decisões dos gerentes são guiados pelos indicadores financeiros da empresa, pelas ofertas do mercado, pelas obrigações legais incontornáveis e pelo comportamento aprendido com seus pais ou com os donos da empresa (BONNIN; BEDR, 2001).

A busca por alternativas voltadas à análise das situações de trabalho nas PME, tais como a Ergonomia de Performance Global da França (BONNIN; BEDR, 2001), o Diagnostic Court, também na França (AGENCE NATIONALE POUR L'AMÉLIORATION DÊS CONDITIONS DE TRAVAIL, 2006; DELTOR; GUERÍN, 1994; DELTOR; THON, 1992), e a Lista de Verificação Ergonômica (LVE), no Brasil (INTERNATIONAL LABOUR OFFICE e INTERNATIONAL ERGONOMICS ASSOCIATION, 2001), evidenciam que, não só no Brasil, mas em outras partes do mundo, a demanda por ações ergonômicas voltadas para as PME é uma realidade, refletindo, presumivelmente, a dificuldade em utilizar os métodos da Abordagem Clássica e da AET nas empresas menores, seja pelo alto custo de tais ações ou pela não conciliação com a demanda e limitação destas.

Quanto aos instrumentos voltados para a PME citados acima, a LVE deve ser vista com certa ressalva, pois há pouco foco nas outras questões que não as físicas se a compararmos com o método AET, recomendado pela NR-17 como meio de avaliação do local de trabalho. Não há na LVE, instrumento tão próximo da abordagem clássica da Ergonomia, espaço para uma visão que não técnica dos problemas, não havendo meios, no momento de aplicação da lista, para diálogo com os trabalhadores, o que permitiria coletar dados sobre a percepção que eles guardam do processo de trabalho, confrontando essa visão com a dos líderes, em termos de demanda para a mudança. Apesar das contrariedades, a LVE tem sua utilidade expressa pela possibilidade de contribuir para a resolução de alguns - ou de muitos - problemas através de criatividade e de um investimento relativamente baixo. O custo praticamente nulo da aplicação dessa lista, uma vez que é facilmente aplicável pelos próprios funcionários responsáveis por gerenciar saúde e segurança, também assegura ser um método interessante quando não há meios de aplicação da AET.

Métodos, tais como o Diagnostic Court, que faz um diagnóstico das demandas da empresa, guiando a ação para áreas prioritárias, auxiliam para que as ações não se desenvolvam de maneira arbitrária e que não haja seleção equivocada dos problemas a resolver. A vantagem desses métodos para abordar empresas de menor porte é que, além de sua completude por permitir essa negociação com os trabalhadores, são instrumentos que focam na real demanda da empresa, fugindo da reestruturação exclusivamente física e construindo novas relações a partir do diagnóstico das situações nas quais se pode intervir. $\mathrm{O}$ Diagnostic Court e metodologias centradas na demanda da empresa também conseguem conciliar-se com outra dificuldade muito evidenciada em estudos gerenciais e em qualquer outro programa desenvolvido para PMEs, que é a dificuldade de homogeneização, devido aos diferentes motivos que levam a empresa a se manter pequena ou aos diversos setores ao qual pertence, necessitando-se também de considerar o acesso a tecnologias, à informação e à disponibilidade de recursos financeiros. O Diagnostic Court apresenta ainda outra vantagem para a PME que consiste na gratuidade de sua aplicação, uma vez que é financiado pela Agence Nationale Pour l'Amélioration dês Conditions du Travail (Anact) da França. Apesar das vantagens da ferramenta supracitada, não foram encontradas, na literatura pesquisada, evidências de sua aplicação no Brasil.

\section{Método}

Diante da evidente dificuldade das empresas de menor porte em desenvolver ações em SST e em Ergonomia eficientemente, também considerando a sua diversidade e a dificuldade sugerida por muitos autores em adaptar mecanismos desenvolvidos para as grandes empresas em ambientes menores, foi feita uma investigação prática sob a forma de estudos de caso e pesquisa qualitativa, entre os meses de abril de 2005 e dezembro de 2006, em três empresas 
industriais de pequeno e médio porte da cidade de São José dos Campos-SP, cidade que, participando com 5,9\% da produção industrial nacional, é um dos centros industriais e de serviços mais importantes do interior Paulista (SERVIÇO BRASILEIRO DE APOIO ÀS MICRO E PEQUENAS EMPRESAS, 2006). Tal estudo visou primeiramente investigar as condições de saúde nesses ambientes para depois investigar a possível dificuldade na inserção de programas de saúde e segurança nas mesmas, principalmente no que se refere à Ergonomia, favorecendo uma reflexão sobre o assunto em questão.

Dispondo de um catálogo fornecido pela Associação de Empresas do Bairro Chácaras Reunidas (ASSECRE) - bairro que concentra a maior parte de empresas da cidade, com mais de 100 empresas de pequeno e médio porte cadastradas -, selecionamos aquelas pertencentes ao ramo industrial. Subseqüentemente, foi feito contato telefônico com 29 dessas empresas, selecionadas aleatoriamente, sendo que apenas três aceitaram fornecer dados para o estudo.

Por convenção, foram adotadas as seguintes siglas para as respectivas empresas estudadas:

- PE-1: Pequena empresa voltada para ferramentaria e estamparia, possuindo 60 funcionários. Produz peças, principalmente, para o setor automobilístico.

- PE-2: A empresa fabrica cabos e componentes para telefonia, sendo uma empresa de médio porte, segundo o gerente. Para o mercado, no entanto, pode aparecer como pequena empresa. Possui 45 funcionários, classificando-se como pequena de acordo com o Serviço Brasileiro de Apoio às Micro e Pequenas Empresas (Sebrae).

- MDE: A empresa pode ser considerada como de médio porte caminhando para grande, pois possui 200 funcionários em seu quadro geral. As atividades da empresa se concentram no setor de autopeças de metalurgia, além de pintura e manutenção de tais peças.

A investigação, baseada em pesquisa qualitativa, consistiu inicialmente na realização de uma entrevista com os responsáveis por gerenciar as ações de saúde e segurança nas empresas e na visita ao chão de fábrica. As questões principais da entrevista foram a respeito da estrutura da empresa, dos processos operados, do número de funcionários, das ações em saúde e segurança desenvolvidas e dos responsáveis por gerenciar tais ações.

Após a coleta dos dados preliminares, houve necessidade de refino das questões que se queria investigar, tendo sido elaborado especialmente para este estudo um novo questionário, que objetivou investigar como são gerenciadas ações em SST no ambiente laboral, como a Ergonomia insere-se nesses ambientes, como é vista a SST e a Ergonomia nessas empresas, bem como sua importância, e quais as possíveis dificuldades em conduzir ações em Ergonomia nas empresas de menor porte. O questionário elaborado para o estudo possui perguntas abertas e fechadas e divide-se em três partes:

- Na primeira parte, são feitas quatro perguntas fechadas sobre a empresa, a saber: porte, tipo, tempo de funcionamento e relacionamento com os trabalhadores.

- Na segunda parte, são feitas doze perguntas fechadas e quatro abertas sobre saúde e segurança, tais como a forma de gerenciamento das ações de saúde e segurança na empresa, as atividades desenvolvidas em termos de saúde e segurança, o uso de EPIs, Normas Regulamentadoras aplicadas na empresa, quem se responsabiliza por fazer cumprir as mesmas, o que é considerado mais ou menos importante, o motivo pelo qual não cumprem algumas normas - caso não as cumpram -, o que acham que poderia ser melhorado em termos de saúde e segurança, até onde acham que a saúde é responsabilidade dos empregadores ou dos trabalhadores, além da opinião dos entrevistados sobre as políticas de SST existentes.

- Na terceira parte, são feitas sete perguntas fechadas, direcionadas à Ergonomia e organização do trabalho, tais como a existência de estudos sobre a organização do trabalho na empresa, o conhecimento que possuem sobre a ergonomia e como vêem suas vantagens para a organização, bem como a disponibilidade em aplicar tais programas nas empresas e o que acham que poderia motivar ações ergonômicas.

O questionário é acompanhado de instruções de preenchimento, o qual alerta ser possível anotar mais de uma resposta quando houver questões de múltipla escolha. Além disso, há espaço para os respondentes anotarem suas opiniões e comentários.

Dentre essas empresas, apenas a PE-1 e a MDE forneceram dados integralmente à pesquisa, tendo a outra firma fornecido apenas dados preliminares a este estudo e alegado, em fases subseqüentes, que não teria tempo disponível para fornecer maiores detalhes à investigação. Abaixo, um breve perfil dos entrevistados:

PE-1: A entrevista foi feita com a diretora de $\mathrm{RH}$; o questionário foi respondido pela presidente da Comissão Interna de Prevenção de Acidentes (CIPA);

PE-2: O dono da empresa forneceu os dados à entrevista;

MDE: A diretora de $\mathrm{RH}$ forneceu os dados à entrevista e o técnico de segurança do trabalho respondeu o questionário.

Uma vez que a entrevista e o questionário foram aplicados em fases distintas do estudo, os dados coletados para ambos foram tratados separadamente. Os dados da entrevista foram transcritos para um relatório; as respostas obtidas nos questionários foram devidamente analisadas e transcritas para outro relatório. Todos os dados coletados podem ser encontrados ao longo do item Resultados e discussão. Considerando 
que, para cada empresa, existe uma percepção e uma postura diferente a respeito da SST e da Ergonomia, deve ficar clara a unicidade de cada caso.

Embora a PE-2 não tenha participado integralmente do estudo, o relato fornecido na entrevista preliminar foi de grande valia para a discussão, justificando sua não exclusão.

\section{Resultados e discussão}

A seguir, os resultados do estudo conduzido nas três empresas em questão. São descritos e discutidos resultados relativos à Saúde e Segurança no Trabalho e à Ergonomia, a saber: profissionais envolvidos nas ações supracitadas; as orientações fornecidas aos trabalhadores e o nível de participação destes nas ações; a forma de avaliação dos resultados das intervenções, assim como a informalidade e a perceptividade em que tais ações são pautadas. Depois, discutem-se as dificuldades encontradas pelas empresas para a realização de ações em SST e em Ergonomia.

\section{Profissionais envolvidos nas ações ergonômicas e de SST nas PME estudadas}

Como resultado de tal investigação, ficou evidente que o gerenciamento da saúde e segurança difere entre as empresas: na PE-1 somente é gerenciada a segurança e quem a gerencia são os membros da CIPA; na PE-2, quem gerencia saúde e segurança, além da CIPA, é o gerente da empresa - fato observado na maioria das empresas da Grã-Bretanha por Bradshaw et al. (2001); na MDE, as ações em SST são gerenciadas por um técnico de segurança do trabalho, que leva as propostas de mudanças para a gerência. Mudanças no local de trabalho - realizadas à luz de conhecimento adquirido em cursos de Ergonomia e em livros sobre o assunto - são realizadas, na PE-2 e na MDE, pelo gerente e pelo técnico de segurança do trabalho, respectivamente.

Uma das principais características evidenciadas nas empresas pesquisadas é a presença de consultores externos para guiar ações relativas à saúde e segurança de seus funcionários, colaboração comum à PME, que, muitas vezes, não possui recursos internos - financeiros, humanos ou estruturais - que permitam conduzir tais ações por si só. Quanto menor for a empresa, maior o apoio recebido desses consultores. Logo, evidências sobre a contratação de consultores, apontadas pelos trabalhos de Rachid et al. (2001) em pesquisa sobre o cumprimento de normas ISO 9001, bem como nos trabalhos de Bradshaw et al. (2001) e de Jung (1999), ambos a respeito de ações em saúde e segurança desenvolvidas, respectivamente, na GrãBretanha e na Coréia, confirmam-se para os casos em questão, seja por que tais serviços saem por um preço reduzido, seja pela não existência de profissionais capacitados pertencentes ao quadro fixo da empresa, esse último fator relacionado não só ao custo de contratação, mas à falta de capacidade dessas empresas em comportar em seu quadro grande diversidade de mão-de-obra - fato evidenciado por La Rovere (2001) e Cardoso (1998). Uma desvantagem que o serviço de consultoria pode apresentar na PME é a sua análise nada holística de seu ambiente, sendo a contratação de consultores geralmente direcionada para um assunto específico (SOARES, 1998).

\section{Orientações fornecidas aos trabalhadores}

As três empresas alegaram orientar seus trabalhadores quanto à segurança. Todas relataram fornecer ao trabalhador as orientações através da Comissão Interna de Prevenção de Acidentes (CIPA) ou de panfletos e pôsteres alocados na empresa, sendo que a MDE e a PE-2 afirmaram prover informações também sobre manutenção da saúde. A PE-1 limitavase a realizar, como medida de saúde, atividades de alongamento antes do início do expediente, mas, por questões financeiras, extinguiu o programa, sendo hoje opção de o trabalhador alongar-se ou não antes do início do turno. Medidas, tais como elaboração de panfletos e pôsteres, também foram identificadas no estudo de Bradshaw et al. (2001) como sendo medidas adotadas pelas empresas de menor porte para orientar quanto à saúde, destacando-se por serem alternativas práticas, de baixo custo e, justamente por isso, facilmente divulgáveis na PME.

A afirmação de que essas empresas oferecem treinamento em algum grau a seus trabalhadores faz inquirir até onde a afirmação de Johansson e Johansson (1992), Champoux e Brun (2001), Jensen et al. (2001), sobre a falta de treinamento e educação nas empresas menores, pode ser considerada válida. Pode ser que o conhecimento não seja transmitido de forma correta, mesmo porque o meio pouco formalizado como são conduzidas as ações e o não estabelecimento de mecanismos claros de comunicação interna nas PME podem favorecer que as informações básicas não sejam transmitidas da forma e no tempo corretos, conforme já afirmou Cardoso (1998). Mesmo que se possa contestar a qualidade da informação provida, não se pode negar que há a (tentativa de) sua transmissão.

\section{A participação dos trabalhadores}

Na PE-1, os trabalhadores não possuem o direito de apresentar propostas ou de participar dos programas relativos à saúde e à segurança, fato comum em algumas empresas de acordo com Miranda e Dias (2004). O pouco espaço para opinar mantém relação com a forma de gerenciamento vivenciada na PE-1, que não permite participação dos trabalhadores, caracterizando-se como regime paternalista, segundo estudo de Biquand et al. (2001). Na referida empresa, há clara centralização do poder, natural em empresas de menor porte, embora esse não seja o único sistema de gerenciamento das PME, que podem ter 
favorecidas a comunicação e a visibilidade por parte de seus gerentes devido à falta de hierarquias, proporcionando uma melhor relação de comunicação entre a chefia e os trabalhadores (GHOBADIAN; GALLEAR, 1996). A comunicabilidade favorecida pela melhor visão é evidenciada na PE-2 e MDE, onde é permitido ao trabalhador participar e opinar, havendo nas empresas citadas a participação dos trabalhadores no Programa de Prevenção de Riscos Ambientais (PPRA) e no Programa de Controle Médico de Saúde Ocupacional (PCMSO).

Quanto à importância do diálogo, é válido argumentar que toda transformação, para corresponder às necessidades de quem usufrui dela, deve ser guiada por seus relatos, suas necessidades, sua percepção sobre o ambiente e sobre o que pode potencialmente ser melhorado. A abordagem situada da Ergonomia valoriza a participação dos trabalhadores no processo de construção da saúde no ambiente de trabalho. Para Biquand et al. (2001), lógicas simplistas, quando não há clara visão dos acontecimentos internos das empresas, apresentam riscos aos empregadores de não conseguirem administrar ações em segurança, tampouco melhorar as condições de trabalho ou controlar adequadamente a gestão de suas firmas. A falta de participação dos trabalhadores, bem como a falta de um confronto entre os achados de uma investigação do local de trabalho e a percepção dos trabalhadores - no tocante aos constrangimentos impostos pela atividade - também interferem, negativamente, na mudança de visão dos trabalhadores para que estes aceitem as melhorias, segundo o mesmo autor.

\section{Forma de avaliação das ações em SST e Ergonomia nas empresas}

Não há, na MDE ou na PE-1, qualquer forma de avaliação e medição formal dos resultados das ações em SST, nem aplicação da AET ou medição dos resultados das ações Ergonômicas na MDE e na PE-2, tendo sido essa tendência evidenciada por Bradshaw et al. (2001) também na Grã-Bretanha. Tal resultado é natural, visto que essas empresas guardam como característica a pouca formalização de seus processos (CARVALHO, 2004; CARDOSO, 1998), havendo, também, ausência de competências internas que apóiem a Ergonomia nessas empresas (BONNIN; BEDR, 2001). Na MDE, as avaliações dos programas voltados à Ergonomia são pautadas na percepção dos atores envolvidos no processo de transformação do trabalho. A afirmação de Cardoso (1998) de que a cultura dessas empresas é informal e perceptiva, sendo as mudanças guiadas de acordo com essa informalidade e percepção, e de Bonnin e Bedr (2001) de que a gestão das PME apóia-se no sentido implícito das coisas, sustenta o resultado encontrado para essas duas últimas empresas. Mesmo havendo dificuldade de mudança cultural, natural de qualquer empresa (CARDOSO, 1998), a vontade de mudar e o reconhecimento dos benefícios das mudanças ultrapassam as barreiras impostas tanto pelos funcionários, quanto pela diretoria, na PE-2 e na MDE.

\section{Ações em SST e em Ergonomia}

Os claros ganhos em termos de aumento da produção e redução do absenteísmo trazidos por mudanças sobre aspectos físicos, cognitivos e organizacionais do trabalho são reconhecidos pela PE-2 e MDE que, informalmente, realizam melhorias no ambiente de trabalho guiadas pelo diálogo entre as diversas hierarquias. A clara visão do valor em investir em ações voltadas ao ambiente de trabalho como garantia da boa saúde de seus funcionários, na MDE e PE-2, contraria a visão conservadora ainda muito difundida de que o trabalhador é responsável por seus atos e por manter sua boa saúde. Essa crença, relatada por Vilela et al. (2004), é ainda vigente em muitos locais, inclusive na PE-1, que atribuiu, há pouco tempo, a culpa de um acidente à desatenção do trabalhador que burlou o sistema bi-manual de uma prensa, não sendo reconhecida, nesse caso, a influência dos fatores físicos do local e das exigências de produtividade que o levaram a tentativa de otimizar o processo de produção. A falta de arranjos de proteção em máquinas e equipamentos das empresas também já fora identificado previamente na Noruega por Bull, Riise e Moen (2002).

Quanto à maneira informal e perceptiva de conduzir melhorias, reconhece-se que essas mudanças informais podem trazer benefícios para as empresas em questão, podendo, segundo Valot (2001), o funcionamento relativo da improvisação se revelar uma gestão da imprecisão capaz de produzir uma adaptação eficaz em um ambiente marcado pela incerteza e pela complexidade. Por outro lado, as conseqüências negativas dessa não formalização dos estudos em SST em nenhuma das três empresas estudadas versam em torno dos riscos destas empresas utilizarem medidas pouco elaboradas, seguindo tendência apontada por Champoux e Brun (2001) da abordagem à gestão em SST, principalmente na $\mathrm{PE}$, não ser feita de maneira sistemática, com seleção arbitrária do que se deve resolver e ações pouco elaboradas. A tempo, nenhuma das empresas visitadas conhecia a LVE, o Diagnostic Court ou qualquer outro método de análise Ergonômica voltado à PME.

\section{Algumas considerações sobre as ações em SST e em Ergonomia nas empresas estudadas}

Os resultados descritos acima nos levam a concluir que, enquanto na MDE e na PE-2 busca-se melhorar as condições de trabalho, na PE-1 há preocupação somente com ações voltadas à segurança e zelo por parte dos trabalhadores, sendo cumprido o mínimo exigido por lei, fatos já evidenciados em outras pequenas empresas estudadas por Bradshaw et al. (2001), Champoux e Brun (2001) e por Rongo et al. (2004). Se dentro da cultura participativa da MDE 
e da PE-2 há certa valorização do trabalhador como agente ativo na mudança, sendo atendidas algumas das reivindicações colocadas por estes quanto a possíveis melhorias no ambiente, dentro da cultura conservadora e paternalista da PE-1 é fácil assumir que o trabalhador deve ser responsável pelos seus atos e prevenir os riscos no local, desprezando o ambiente como contribuinte dos eventos traumáticos. Rememorando que a conduta não é somente a parte observável do ato e que os acidentes podem ser também resultado de disfunção do sistema, não sendo uma simples questão de atenção ou desatenção às normas (observações feitas por Dejours, 2003; Neboit, 2003 e Vilela et al. 2004), fica expressa a importância de medidas voltadas a transformar o trabalho.

\section{As dificuldades encontradas pela PE-1 e pela MDE para desenvolver programas de SST}

Para os casos estudados, distintos agentes promovem a dificuldade da disseminação da Ergonomia e de ações em SST, havendo razões diversas para a forma como são conduzidas as ações.

Na PE-1, a opção por consultores externos - atuantes em tempo parcial - para desenvolver parte das ações deve-se à falta de recursos financeiros para manter profissionais contratados em tempo integral, de estrutura e, complementarmente ou conseqüentemente, de competências internas para apoiar esses profissionais dentro da empresa. Logo, as dificuldades financeiras, caracterizadas inclusive pela falta de crédito subsidiado e de apoio específico a essas empresas, evidenciadas pelos estudos de Soares (1998), La Rovere (2001) e Lemos (2003), motivam a falta de investimentos em saúde, assegurando, para este caso, a veracidade dos argumentos de Sohn et al. (1998), Champoux e Brun (2001) e Jensen et al. (2001) sobre a influência exercida pela disposição de recursos financeiros no alcance das atividades em SST. Refuta, portanto, a afirmação de De Kok (2005) de que as condições econômicas não repercutem sobre a opção da empresa em não investir em ações preventivas. A falta de estrutura e de competências internas na PE-1, referidas pela entrevistada como um dos dificultadores de tais ações e anteriormente descritas por La Rovere (2001), Cardoso (1998), Coriat (1994) e Rachid et al. (2001), refutam, para esse caso, a afirmação de Jensen et al. (2001) de que, para conduzir ações de SST nas empresas menores, basta qualificar alguém de dentro da empresa a partir de um treinamento. Frente a tal possibilidade, é interessante rememorar Ghobadian e Gallear (1996), que acreditam que o treinamento em PME é limitado devido aos poucos recursos humanos, aos poucos profissionais qualificados e aos constrangimentos financeiros enfrentados.
A falta e a forma de utilização dos recursos na PE-1 (GHOBADIAN; GALLEAR, 1996), motivadas pela instabilidade e pela vulnerabilidade, dificultam ao líder da empresa disponibilizar o seu tempo para trabalhar com saúde e segurança - confirmando assim os argumentos de De Kok (2005) e Walters (2002) - e somam-se à necessidade de manter ações prioritárias do ponto de vista do gerente para a sobrevivência da empresa, principalmente quando esta está vivenciando a "fase heróica", pela qual o dono da empresa faz tudo. Nesse caso, a Ergonomia só encontrará espaço para inserção quando a empresa vivenciar seu momento de crescimento, que possibilitará a recriação desse ambiente e de novos investimentos (informação verbal) ${ }^{3}$. É difícil para uma empresa que não tem incorporada a Ergonomia adotá-la, nesse momento, em uma tentativa de sobrevivência, visto o custo de novos maquinários e das demais modificações propostas.

Na PE-1, também a cultura aliada ao modelo gerencial e não somente à falta de recursos financeiros ou de pessoas foi evidenciada como entrave às ações ergonômicas, principalmente ao considerarmos que, dentro da abordagem situada, que engloba a AET e a negociação dos constrangimentos, assim como para outras ações em SST, a participação dos trabalhadores pelo provimento de sua percepção é considerada necessária. O claro autoritarismo com que a gerência se relaciona com os trabalhadores e o modelo paternalista assumido contribuem para a não construção de ações, já que não é oferecida ao trabalhador a oportunidade de opinar. Os membros da CIPA não conseguem driblar a pouca vontade da gerência em atender às reivindicações dos trabalhadores (fato não exclusivo desta empresa ou de empresas de pequeno porte).

As conseqüências do modelo paternalista, descrito por Biquand et al. (2001), são os desarranjos e a falta de equilíbrio na relação com os trabalhadores, evidenciando que quanto menor a comunicação, mais difícil entender as necessidades do trabalhador, o que resulta em equívocos de julgamento. Conforme já dito por Cardoso (1998), não se pode esperar que processos participativos de busca por melhorias funcionem perfeitamente quando aplicados em organizações altamente centralizadas, onde um manda e os outros obedecem, de preferência, sem discutir.

A cultura de causalidade de acidentes sob responsabilidade do trabalhador seria o que leva a PE-1 a assumir ações mais voltadas à segurança do que à saúde, tais como a promoção do uso dos EPIs e orientação quanto aos atos seguros, confirmando o argumento de Bradshaw et al. (2001), Champoux e Brun (2001) e Rongo et al. (2004) de que algumas empresas gerenciam saúde ocupacional privilegiando ações em segurança.

${ }^{3}$ DUARTE, J. F. C. M. Comunicação pessoal em qualificação de dissertação de mestrado. Fevereiro/2006. 
Analisando a MDE, a disponibilidade de recursos financeiros não foi apontada pelo seu entrevistado como dificultador de ações em SST, portanto, tal assertativa não pode ser considerada principal agente limitador neste caso, nem foi apontada impossibilidade de treinar um profissional de dentro da empresa para gerenciar ações em SST, mesmo porque na empresa há um técnico de segurança que busca aprimorar seus conhecimentos na área de SST e Ergonomia. Fato é que, mesmo informalmente, busca-se cumprir as normas em Ergonomia. Consideram-se, nessa empresa, além de sua maior disponibilidade de recursos e melhor acesso ao conhecimento, dois agentes facilitadores para a entrada de ações em SST e da Ergonomia: o modelo gerencial assumido e a vontade de mudar. Há na MDE valorização do trabalhador como agente ativo na mudança da empresa, opinando, fornecendo sua percepção sobre o que pode ser melhorado, sendo o modelo gerencial dessa empresa um modelo administrativo, seguindo a definição de Biquand et al. (2001). Ainda, há na empresa o reconhecimento da importância da Ergonomia, além da clara visão sobre o que ela realmente é; estão inclusive tentando montar um comitê próprio de Ergonomia. Foi apontado como agente dificultador de toda ação na empresa a resistência à mudança cultural, principalmente por parte dos gerentes, mesmo que entre eles haja reconhecimento da importância da Ergonomia (inclusive para o bom desempenho da produtividade) e de ações providas pela empresa para assegurar saúde e segurança, embora isso não impeça mudanças. Essa resistência à mudança cultural já foi apontada por Cardoso (1998) e atesta-se como verossímil, sendo apoiada pela afirmação de Duarte e Feitosa (1998) de que entre o desejo de ver melhorias e a aceitação dessa mudança, há uma distância que nem sempre a empresa almeja verdadeiramente encurtar.

Pode-se dizer que, mesmo ante certa resistência à mudança, a PE-2 e a MDE expressam um reconhecimento do valor de ações sobre a saúde e segurança, reconhecendo também que não só o trabalhador, mas também a empresa possuem responsabilidades sobre tais ações. Enquanto na PE-1 está explícito que os trabalhadores devem ser os responsáveis por zelar pela sua saúde, nesta última, mesmo quando houve acidente com a prensa, não se assumiu que a máquina apresentava déficit de segurança, tendo sido atribuída toda a responsabilidade sobre a causa do acidente à vítima. Tal resultado condiz com os dados obtidos em pesquisa por Bradshaw et al. (2001), que viu que, apesar da maioria dos empregadores achar a saúde importante para o andamento da firma, não está claro em que nível os empregadores devem se responsabilizar, embora haja unanimidade em considerar que o trabalhador deve ser responsável pela sua saúde.

A consulta aos órgãos de apoio às PME, tais como o Serviço Social da Indústria (SESI) e o Sebrae, evidenciam, para a cidade em questão, não haver qualquer programa que favoreça a informação sobre os benefícios da Ergonomia para as empresas, tampouco programas que incentivem seu uso nas PME. Há, no SESI, incentivo à boa saúde no que diz respeito à orientação sobre alimentação, controle da pressão arterial, além de outras dicas de saúde, mas não há nada voltado ao incentivo à Ergonomia. Em outros estados, como, por exemplo, no Rio Grande do Sul, o Sebrae e o SESI desenvolvem ações voltadas à SST e Ergonomia nas empresas, estimulando a disseminação da última através da promoção de análises em empresas menores. Quanto à divulgação da LVE na cidade sede do estudo, há indícios de fraca divulgação da ferramenta, assim como é com outras medidas mais simples, sendo que nenhuma das empresas visitadas, nem mesmo o Sebrae ou o SESI, conheciam a LVE.

\section{Alternativas para uma melhor inserção da Ergono- mia nas PME}

Seja pelo pouco esclarecimento sobre a disciplina Ergonomia, seja pelo conservadorismo e pela crença de causalidade de acidentes como responsabilidade do trabalhador, ou ainda pela dificuldade de conduzir ações formalmente nas empresas, mesmo onde elas são aceitas, fica expressa a necessidade de desenvolver ferramentas adaptáveis às PME do Brasil aliadas a políticas de informação e esclarecimento, o que poderia quebrar alguns paradigmas e minimizar a não aceitação dessas ações.

Empresas em que impera a falta de clareza sobre a importância das ações em SST e dos possíveis ganhos com a Ergonomia não abrem espaço para a introdução desta última. Haslam (2002) argumenta que as ações dos indivíduos são moldadas por seus conhecimentos, habilidades, hábitos e desejos, os quais, por sua vez, são influenciados por aspectos psicológicos e sociais. Não só prover informação aos líderes, mas também aos operadores é essencial para que seja possível a ambos entenderem o benefício de uma melhoria. Para Haslam (2002), este entendimento é provido através de um processo de educação, treinamento, encorajamento e feedback, caso seja necessário adotar uma maneira diferente de realizar uma tarefa ou utilizar uma máquina redesenhada.

De fato, o conhecimento e o provimento de informação colocam-se como pilares para a construção de ações ergonômicas, fazendo surgir uma nova realidade, em que a provisão da saúde é algo real e efetivo, favorecida pelo ambiente de trabalho. Conhecer os riscos à saúde não implica necessariamente em reconhecer a importância da Ergonomia, e é por isso que prover informação sobre a disciplina, não só para empregadores, mas também para trabalhadores é algo essencial para a aceitação desta. O Reino Unido coloca-se como exemplo de país que buscou, a partir de campanhas tais como Good Health is Good Business e Improving Access to Occupational Health Support, promovidas pelo Health and Safety Executive e Health 
and Safety Comission, reverter esse quadro característico de pouca informação, promovendo reconhecimento, por parte do empregador, da importância de programas de saúde e segurança em seus negócios (BULL et al., 2002). Neste país, fora identificada uma deficiência na provisão de informação para empregadores sobre a importância de ações em SST, evidenciando que o motivo da pouca ação sobre a saúde dos trabalhadores não era a falta de vontade de agir, mas sim a falta de conhecimento sobre como agir.

Analisando os efeitos positivos do provimento da informação sobre Ergonomia, Jensen et al. (2001) perceberam que, além de ter favorecido a obtenção de cooperação e clima psicológico, os empregados entenderam facilmente a abordagem básica apresentada e implementaram um número de melhorias que afetaram positivamente tanto a produtividade, quanto o ambiente de trabalho.

Além do provimento de informação, também deve ser considerada a importância da elaboração de políticas que incentivem a adoção de programas voltados à melhoria das condições de saúde e segurança no trabalho. Rongo et al. (2004) dizem que a falta de políticas claras no setor informal e a pobreza de locais de trabalho permanentes não encorajam investimentos na área de saúde ocupacional e segurança, mesmo que empregadores e empregados estejam conscientes dos riscos à saúde e à segurança no ambiente laboral. Tal assertiva confirma-se para o Brasil, onde algumas (ou muitas) empresas cumprem o mínimo estabelecido por lei pela própria desobrigação de que elas mantenham profissionais da área de saúde ou segurança, mesmo que o grau de risco de suas atividades seja alto - no caso de empresas com menos de 50 funcionários, há desobrigação de Serviços Especializados de Engenharia de Segurança e Medicina do Trabalho -, ou mesmo pela falta de estrutura.

Diante das dificuldades em desenvolver ações ergonômicas, seja pelo custo, pela falta de informação, de estrutura, ou mesmo por questões culturais e gerenciais, o certo seria buscar, paralelamente ao estabelecimento de algumas políticas, o desenvolvimento e o provimento de ações que possibilitassem a introdução da Ergonomia nas PME, já que esta é capaz de reduzir os riscos inerentes ao trabalho. Digo prover, pois acredito que, diante das dificuldades vivenciadas, as empresas menores necessitam de fato desse apoio para que não só a situação de saúde encontre um caminho para melhora, mas também para que essas empresas experimentem um desenvolvimento pautado tanto no bem-estar de seus funcionários, quanto nos objetivos da companhia.

A falta de políticas direcionadas ao bem-estar do trabalhador pode trazer desestímulo ou desinteresse por outras iniciativas que não abordagens focadas na segurança, havendo equívoco quanto à importância de desenvolver tais ações, as quais acabam sendo relacionadas como que pertinentes somente às grandes empresas, conforme relato colhido na PE-1, que considerava a Ergonomia um projeto essencial somente para aquelas. Outro fator contribuinte para o não desenvolvimento de ações ergonômicas é a determinação legal para que mudanças somente sejam feitas nas empresas após um auditor fiscal visitar o estabelecimento e, a partir de uma avaliação, determinar o que deve ser mudado em termos de adequação do posto de trabalho.

A ausência de ações ergonômicas configura-se como prejudicial não só para trabalhadores, que perderão em termos de saúde, segurança e melhora de sua produtividade individual, mas também para a empresa, que pode sofrer perdas na produtividade global, configuradas pela ineficácia na operação dos equipamentos projetados para determinadas atividades, bem como nos resultados esperados dos sistemas de trabalho, com conseqüente redução do desempenho competitivo e aumento do absenteísmo laboral (MAFRA, 2004). A informalidade na condução de ações ergonômicas mesmo em empresas que tentam desenvolver ou desenvolvem programas em Ergonomia, caracterizada pela intuição e improvisação de soluções, reforça a necessidade de políticas e, quem sabe, até financiamento público a programas de Ergonomia nas empresas.

\section{Considerações finais}

Simplesmente instruir quanto à segurança não garante que tudo correrá bem. Organizar o trabalho é essencial para que a mudança seja de fato eficaz para eliminar fatores de risco no trabalho, tanto em questão de segurança, quanto de saúde, não só contribuindo para diminuição de acidentes, mas também para a prevenção de doenças relacionadas ao trabalho. A prevenção de LER/DORT também está relacionada aos fatores organizacionais da empresa, contribuindo conjuntamente para a melhoria da produtividade.

É necessário desenvolver medidas de estímulo, provisão e fomento à Ergonomia nas empresas de menor porte, instrumentos flexíveis que possam adaptar-se e atender às diferentes necessidades impostas pela individualidade de cada caso, entre empresas caracterizadas pela coexistência, em umas, de baixa incorporação tecnológica e, em outras, de alta flexibilidade e inovatividade. Cada análise deve trabalhar os conflitos entre os atores envolvidos para então trazer respostas para a melhora do ambiente de trabalho e para a construção de uma ação ergonômica.

Ainda, é preciso pensar em novas alternativas de inclusão de programas de Ergonomia nos ambientes industriais, os quais atinjam todos os níveis institucionais e estruturais, quiçá propondo um programa público de orientação e institucionalização da Ergonomia. 


\section{Referências}

AGENCE NATIONALE POUR L'AMÉLIORATION

DÊS CONDITIONS DE TRAVAIL. Le diagnostic Court. [1994?]. Disponível em: http:www.anact.fr. Acesso em: 21 mar. 2006.

BRADSHAW, L. M. et al. Provision and perception of occupational health in small and medium-sized enterprises in Sheffield, UK. Occup. Med., London, GB, v. 51, n. 1, p. 39-44. Feb. 2001.

BIQUAND, S.; LABILLE, B.; CHRISTELLE, C. Management et Ergonomie: conduite du changement dans les petites structures. In: CONGRÈS SELF-ACE, 2., 2001, Montréal. Les transformations du travail, enjeux pour l'ergonomie. 1 CD-ROM.

BONNIN, D.; BEDR, B. Développement du conseil en ergonomie: vers une prestation de conseil élargie destine aux très petites, petites et Moyennes enterprises (TPE-MPE), l'ergonomie de la performance globale. In: CONGRÈS SELF-ACE, 2., 2001, Montréal. Les transformations du travail, enjeux pour l'ergonomie. 1 CD-ROM.

BORTOLI NETO, A. Tipologia de problemas das pequenas e médias empresas. 1980. $201 \mathrm{f}$. Dissertação (Mestrado em Administração) - Faculdade de Economia, Administração e Contabilidade, Universidade de São Paulo, São Paulo, 1980.

BULL, N.; RIISE, T.; MOEN, B. E. Work-related injuries and occupational health and safety factors in smaller enterprises - a prospective study. Occup. Med., London, GB, v. 52, n. 2, p. 70-74, mar. 2002.

CAMPANHOLE, A.; CAMPANHOLE, H. L. Consolidação das leis do trabalho e legislação complementar. 88. ed. Rio de Janeiro: Atlas, 1993. $744 \mathrm{p}$.

CARDOSO, V. C. Estratégia, processos e operações para pequenas e médias empresas: um método sintético para tornar negócios de pequeno porte auto-sustentáveis no longo prazo. 1998. $151 \mathrm{f}$. Dissertação (Mestrado em Engenharia de Produção) - Universidade Federal do Rio de Janeiro, Rio de Janeiro, 1998.

CARVALHO, K. C. Gestão das informações sobre o ambiente na pequena empresa: estudo comparativo de casos sobre o processo estratégico no setor de serviços (hoteleiro) da região de Brotas - SP. 2004. 235 f. Dissertação (Mestrado em Engenharia de Produção) - Escola de Engenharia de São Carlos, Universidade de São Carlos, São Carlos, 2004.

CHAMPOUX, D.; BRUN, J. P. Le Développement de Grilles d'auto-diagnostic dês risques pour lês petites enterprises: une approche pragmatique et concertée à la prise en charge de la santé et de la sécurité du travail. In: CONGRÈS SELF-ACE, 2., 2001, Montréal. Les transformations du travail, enjeux pour l'ergonomie. 1 CD-ROM.
CORIAT, B. Pensar pelo avesso: o modelo japonês de trabalho e organização. Rio de Janeiro: Revan, UFRJ, 1994. $212 \mathrm{p}$.

DE KOK, J. M. P. Precautionary actions within small and medium-sized enterprises. Journal of Small Bussiness Manage., Morgantouen, Wa., v. 43, n. 4, p. 498-516, oct. 2005.

DEJOURS, C. O fator humano. 4. ed. Rio de Janeiro: Fundação Getúlio Vargas, 2003. 104 p.

DELTOR, S; GUERÍN, F. Lês enseignements et lês suítes de l'evaluation. In: BOUTTERIN, C.; DELTOR, S.; GUERÍN, F. Évaluation du diagnostic court. Les Cahiers de L'anact, Montrouge, France, n. 1, mar. 1994. p. 31-37.

DELTOR, S.; THON, P. A propôs du diasgnostic court de l'ANACT ou... Lê diagnostic... Court Peutil Exister? Performances Humaines et Techniques, Toulouse, France, n. 58, p. 16-19. mai./juin. 1992.

DUARTE, F.; FEITOSA, V. (Org.). Linguagem e trabalho. Rio de Janeiro: Lucena; COPPE/UFRJ, 1998. $238 \mathrm{p}$.

GHOBADIAN, A.; GALLEAR, D. N. Total quality management in SMEs. Omega, London, v. 24, n. 1, p. 83-106, feb. 1996.

HASLAM, R. A. Targeting ergonomics interventions: learning from health promotion. Appl. Ergon., England, v. 33, n. 3, p. 241-249, may. 2002.

INTERNATIONAL ERGONOMICS ASSOCIATION. What is ergonomics. Disponível em: www.iea.cc. Acesso em: 10 ago. 2003.

INTERNATIONAL LABOUR OFFICE ; INTERNATIONAL ERGONOMICS ASSOCIATION. Pontos de verificação ergonômica: soluções práticas e de fácil aplicação para melhorar a segurança, a saúde e as condições de trabalho. São Paulo: Fundacentro, 2001. 327p.

JENSEN, P. L.; ALSTRUP, L.; THOFT, E. Workplace assessment: a tool for occupational health and safety management in small firms? Appl. Ergon., England, v. 32, n. 5, p. 433-440, oct. 2001.

JOHANSSON, J.; JOHANSSON, B. Work environment functions in small enterprises in Sweden. Appl. Ergon., England, v. 23, n. 2, p. 91-94. Apr. 1992.

JUNG, M. H. The prospect for occupational health nursing activities in small and medium sized workplaces. J. Occup. Health, Japan, v. 41, n. 1, p. 47-50, jan. 1999.

LA ROVERE, R. L.; CARVALHO, R. L. Cooperação entre pequenas empresas e desenvolvimento local. Rio de Janeiro, 2001. Disponível em: http:// aplicaciones.icesi.edu.co/ciela/anteriores/Papers/ pmed/14.pdf. Acesso em: 03 fev. 2006. 
LEMOS, C. R. Micro, pequenas e médias empresas no Brasil: novos requerimentos de políticas para promoção de sistemas produtivos locais. 2003. 263 f. Tese (Doutorado em Engenharia de Produção) - Universidade Federal do Rio de Janeiro, Rio de Janeiro, 2003.

MAFRA, J. R. D. Economia na ergonomia: metodologia de custeio baseado no modelo operante. 2004. 211 f. Tese (Doutorado em Engenharia de Produção) - Universidade Federal do Rio de Janeiro, Rio de Janeiro, 2004.

MIRANDA, C. R.; DIAS, C. R. PPRA/PCMSO: auditoria, inspeção do trabalho e controle social. Cad. Saúde públ., Rio de Janeiro, v. 20, n. 1, p. 224232, jan./fev. 2004.

NEBOIT, M. Abordagem dos fatores humanos na prevenção de riscos do trabalho. In: MINISTÉRIO DO TRABALHO E EMPREGO. Secretaria de Inspeção do Trabalho. Caminhos da análise de acidentes do trabalho. Brasília: 2003. 102 p.

PINHEIRO, M. Gestão e desempenho das empresas de pequeno porte. 1996. 269 f. Tese (Doutorado em Administração) - Faculdade de Economia, Administração e Contabilidade, Universidade de São Paulo, São Paulo, 1996.

RACHID, A.; BRESCIANI FILHO, E.; GITAHY, L. Relações entre grandes e pequenas empresas de autopeças e a difusão de práticas de gestão da produção. Gestão \& Produção, São Carlos, v. 8, n. 3, p. 319-333, dez. 2001.

RODRIGUES, M. E. O conhecimento nas micro e pequenas empresas: um estudo sobre a absorção e utilização nas micro e pequenas empresas fluminenses. 2000. $158 \mathrm{f}$. Tese (Mestrado em Administração) - Universidade Federal do Rio de Janeiro, Rio de Janeiro, 2000.

RONGO, L. M. B. et al. Occupational exposure and health problems in small-scale industry workers in Dar es Salaam, Tanzania: a situation analysis. Occup. Med., London, v. 54, n. 1, p. 42-46, jan. 2004.
SERVIÇO BRASILEIRO DE APOIO ÀS MICRO E PEQUENAS EMPRESAS. Conheça a Região. São José dos Casmpos. s/d. Disponível em: http://www. sebraesp.com.br/principal/sebrae\%20no\%20estado/ ersaojosedoscampos/conheca_regiao.aspx. Acesso em: 01 nov. 2006.

SOARES, I. S. A engenharia de produção e a pequena e média empresa - PME: uma abordagem sobre competitividade. 1998. 213 f. Tese (Doutorado em Engenharia de Produção) - Universidade Federal do Rio de Janeiro, Rio de Janeiro, 1998.

SOHN, H. S.; LEE, S. K.; LEE, C. U. The effect on workers knowledge, attitudes and behavior of a group health care program for small-sized plants in Pusan, Korea. J. Occup. Health, Tokyo, v. 40, n. 3, p. 236-239, july. 1998.

TORP, S.; MOEN, B. E. The effects of occupational health and safety management on work environment and health: a prospective study. Appl. Ergon., England, v. 37, n. 6, p. 775-783, nov. 2006.

VALOT, C. Pour une ergonomie du changement dans les organisations. In: CONGRÈS SELF-ACE, 2., 2001, Montréal. Les transformations du travail, enjeux pour l'ergonomie. 1 CD-ROM.

VILELA, R. A. G.; IGUTI, A. M.; ALMEIDA, I. M. Culpa da vítima: um modelo para perpetuar a impunidade nos acidentes do trabalho. Cad. Saúde públ., Rio de Janeiro, v. 20, n. 2, p. 570-579, mar./abr., 2004.

VILLELA, A.; AMADEO, E. Geração de empregos privados. In: Projeto nacional de desenvolvimento para micro e pequenas empresas, Rio de Janeiro: COPPEAD/UFRJ, 1994.

WALTARI, L. et al. Ergonomics in small workplaces with special reference to occupational health services. Scand. J. Work Environ. Health, Finland, v. 5, p. 24-29, 1979. Supplement 2.

WALTERS, D. Health and safety in small enterprises: strategies for managing improvement. Occup. Med., United States, v. 52, n. 4, p. 233-234, June, 2002. 